\title{
The "ghost" nerve alias sartorial branch of the saphenous nerve: a proof of scientific negligence!
}

\author{
Georg Christoph Feigl, Friedrich Anderhuber \\ Institute of Anatomy, Medical University Graz, Graz, Austria
}

\begin{abstract}
Misinterpretation of terminology or new creations of anatomical terms can be observed worldwide. Occurring problems because of these invalid terms might be highlighted by an example. During a literature research concerning the saphenous nerve, the sartorial branch of the saphenous nerve was found. As this nerve does not exist in anatomical textbooks as well as in anatomical terminology, we searched for the origin of this branch. In a publication from more than 30 years ago, the reason of the creation of this odd nerve was dyslexia of some authors, reading "sartorial" instead of "saphenous". This gives reason to think about the pressure at universities to focus only on quantity and not on quality of papers. Literature research is sloppy as well as poor; the knowledge sometimes is even poorer, and in addition time to analyse the content of textbooks and papers are not taken. More dreadful is the fact that the manuscript underwent the regular review process, which indicates that the reviewer did not provide the anatomical knowledge as well. Therefore we are all, as scientist or reviewer, always required to research properly and to review only if we are sure to provide the responsibility of a correct judgement together with the anatomical background.
\end{abstract}

Keywords: anatomy; saphenous nerve; terminology

Anatomy 2015;9(2):112-114 (C2015 Turkish Society of Anatomy and Clinical Anatomy (TSACA)

\section{Introduction}

The use of a valid and common terminology would be an ideal base that all medical specialties are able to correspond with and to understand each other. Latin had been the "united" language which had been used for centuries; English partially replaced this language some decades ago. As a consequence, the IFAA (International Federation on Anatomical Associations $)^{[1]}$ included the English terms in the "International Anatomical Terminology". Unfortunately this "terminology" is not well accepted or frequently used by clinicians. What is more, clinicians and even anatomists partially are not aware that this terminology exists. Subsequently, the denial of the existing and valid anatomical terminology leads to a creation of a "new" clinical terminology which might be different among the various fields. One of the worst cases might be that new terms are created due to lacking knowledge. However, the creation of an internationally accepted terminology is not only deserved but more desperately needed. We would like to show this problem presenting following example: the sartorial branch of the saphenous nerve (SBSN).

We stepped over this SBSN during a literature research for saphenous nerve blocks for regional anaesthetic purposes. The nerve is mentioned by Sabat and Kumar. ${ }^{[2]}$ The authors list the sartorial branch (SBSN) as one terminal branch, the second to be the infrapatellar branch (IPBSN) of the saphenous nerve, by describing: "The saphenous nerve exits the adductor canal with the saphenous branch of the inferior geniculate artery and divides promptly in its two terminal branches: the infrapatellar branch and the SBSN. The sartorial branch takes a vertical course as it travels down the medial knee behind the sartorius in close association with gracilis over a length of a few centimeters before becoming subcutaneous by piercing the fascia. It then continues distally with the great saphenous vein to govern sensation of the medial aspect of the leg and ankle". Some of the readers might be confused now, because the above described course of the so called SBSN is quite similar to regularly well known topography of the main saphenous 
nerve at level of knee, leg and ankle. This is in contrast to the known knowledge presented in "Terminologia Anatomica" ${ }^{[1]}$ and several anatomical textbooks such as Gray's Anatomy, who mentions the saphenous nerve, its infrapatellar branch and branches to the leg. ${ }^{[3]} \mathrm{Haffer}^{\left[{ }^{[4]}\right.}$ and Rauber-Kopsch ${ }^{[5]}$ present exactly the same anatomical facts as Gray's Anatomy. Inspecting special clinical textbooks focusing on regional anaesthesia, Meier and Büttner ${ }^{[6]}$ provide the saphenous nerve with the same branching as provided by anatomical textbooks. This does not change in Hadziz's book ${ }^{[7]}$ about peripheral nerve blocks, or in the textbook written by Niesel and van Aken. ${ }^{[8]}$ However, Sabat and Kumar list some papers as references for confirming the anatomy of this nerve. ${ }^{19-}$ ${ }^{12]}$ What is more, Sabat and Kumar present a figure enclosed in their publication, which defines innervation area of the sartorial branch distally to the IPBSN innervation area (abbreviated with "I") and abbreviated it with an "S". This is confusing, because as the sartorius muscle ends at knee level, so as a consequence one can ask from which structure the sartorial branch got its name from. As the authors listed no anatomical textbook, we have to take a precise look on the reference list of the publications and the included Figure 1 of this publication, too. Latter figure is mentioned directly after the statement: "The saphenous nerve supplies cutaneous sensation of the medial aspect of the knee, lower leg and ankle". In addition, this statement is assigned to Bertram et al. ${ }^{[13]}$ Unfortunately, neither the figure nor the sartorial branch can be found in the publication of Bertram et al. ${ }^{[13]}$ So, where does this figure really come from? The publication of Sanders et al. ${ }^{[1]}$ provides more detail because the presented figure is almost exactly the same as in Sabat and Kumar's publication. ${ }^{[2]}$ The legend gives more information that the illustration was included with the permission from Sage publications and copyright 1979 by the American Orthopedic Society for Sports Medicine. Most important is the mentioned year 1979 in which there might be found the next clue on our research for the SBSN. Regarding the already listed references published in 1979, there remains the paper of Hunter et al. ${ }^{[14]}$ In a latter publication the same image with the same distribution, infrapatellar and sartorial branch can be identified as in the manuscript of Sabat and Kumar. ${ }^{[2]}$ Regarding the figure's legend properly, it is stated to be patterned after Cunningham's Textbook (11th Edition), ${ }^{[15]}$ more precisely from an image on page 760 (Figure). Therefore, we looked for this strange nerve in this well known and respected textbook and were not that surprised that the sartorial branch was not listed either in the text, figure legend or in any figure. In addition, we checked the ninth and twelfth edition to be on the safe side, with the same result: no sartorial branch was ever mentioned. So there remains only one possibility. Hunter et al. misinterpreted the figure in Cunningham's textbook and did not read properly enough. As a consequence, the area of innervation allocated to the saphenous nerve, as clearly defined in Cunningham's textbook, became the sartorial branch. As both of them begin with "S", the abbreviation has never been questioned again. Even more, Arthornthurasook and Gaew- $\operatorname{Im}^{[9]}$ revitalized this nerve by their own investigation on the sartorial branch to be followed by Dunaway ${ }^{[10]}$ and Sanders. ${ }^{[2]}$ All of these authors investigated a well-known nerve supposedly believing of assessing a new structure.

This fact let arise some very serious concerns about scientific way of preparing, writing and publishing manuscripts. As most of the young scientists have to work under an increasing pressure of universities, to publish as many papers per year as possible, there is a high risk that quality of literature research might decrease. Due to the time consuming review of literature some might be enticed to take all information of older manuscripts without questioning. Regarding the manuscript of Sabat and Kumar, ${ }^{[2]}$ they even did not include all of the quite low number of publications concerning the sartorial branch. They failed to list Dunaway et al. ${ }^{[10]}$ Certainly we agree that such already published manuscript should include only reviewed and correct information, the manuscript of Sabat and Kumar ${ }^{[2]}$ confirms the opposite. After the motto "fast, many and high", most scientists are measured by number of publications per year, the higher the impact factor the better it is. Unfortunately, this cannot allow a proper literature research.

Another alarming circumstance is that manuscripts often are prepared by scientifically not experienced workers. The problem is that any assistant has to start scientific working someday. It is therefore very important that he is not only supervised, but also guided by an experienced scientist getting in touch with science. Everybody will agree that nobody is able to create the perfect paper with his first attempt. What is more, the inexperienced assistant has to be guided by the experienced step by step. Such a process might take some time. Well, the ideal way before submitting a manuscript to a journal would be a revision by all co-authors, most important the senior author who has to play the role of the supervisor of the entire investigation. This process is even more time consuming and therefore in great danger 
being bypassed. Finally, as the senior author regularly is the most experienced person who additionally provides the soundest knowledge, the manuscript should be submitted after his final approval. However, we assume that in many cases the supervisor does not take the time to correct the manuscript in its final stage. Even more: let us ask honestly? Do we always follow the ideal path or don't we sometimes take the short cut?

In any way, even if the manuscript is submitted with several errors, missing literature, wrongly interpreted statements or no proper literature research, there is still the peer reviewed journal, where such manuscripts have to be rejected or at least being judged with a major revision. More important are the reviewer's comments to highlight weaknesses, errors, or lacking literature. As a consequence, a journal with all its different positions, from the editor to the reviewers, has a very high and important responsibility. The editor or assistant editor needs to find reviewers who are able to deal with the submitted manuscript due to their experience. However, in case of not being an expert of this field, such a reviewer should decline to review and propose somebody who CAN deal with the manuscript correctly and responsibly. The worst case would be that he agrees in reviewing the manuscript without the expertise. Anybody will agree that such a review will not provide the desired quality. What is more, this might lead to an acceptance of manuscripts including errors, misinterpretations and lack of important literature. The amazing but additionally alerting fact is that the error of the manuscript listed above happened more than thirty years ago to be followed by other scientists investigating the sartorial branch of the saphenous nerve without questioning if this nerve really exists. Sometimes it might be quite helpful to read more than one anatomical textbook. If time does not allow such steps, there still remains to ask the expert called experienced anatomist.

\section{References}

1. Federative Committee of Anatomical Terminology (FCAT). Terminologia Anatomica. Stuttgart: Thieme; 1998.

2. Sabat D, Kumar V. Nerve injury during harmstring graft harvest: a prospective comparative study of three different incisions. Knee Surg Sports Traumatol Arthrosc 2013;21:2089-95.

3. Standring S. Nervous System. In: Gray's anatomy, 38th ed. New York: Churchill Livingstone, 1995. p. 1280-2.

4. Thiel W. Membrum inferius. In: Hafferl A, editor. Lehrbuch der topographischen Anatomie. 2nd ed. Heidelberg: Springer; 1969. p. 818-9.

5. Leohnardt H. Plexus lumbalis. In: Rauber/Kopsch Anatomie des Menschen. Stuttgart: Thieme; 1988. p. 490-2.

6. Meier G, Büttner J. Atlas der peripheren Regionalanästhesie. 3rd ed., Stuttgart: Georg Thieme Verlag; 2013. p. 159.

7. Hadzic A, Vloka JD. Peripheral nerve blocks: Principles and practice. New York: McGraw-Hill; 2004, p. 16-7.

8. Niesel HC, Van Aken H. Lokalanästhesie, regionalanästhesie, regionale Schmerztherapie. Stuttgart: Georg Thieme Verlag; 2003. p. 310 .

9. Arthornthurasook A, Gaew-IM K. The sartorial nerve: its relationship to the medial aspect of the knee. Am J Sports Med 1990; 18:41-2.

10. Dunaway DJ, Steensen RN, Wiand W, Dopirak RM. The sartorial branch of the saphenous nerve: its anatomy at the joint line of the knee. Arthroscopy 2005; 21: 547-51.

11. Sanders B, Rolf R, McClelland W, Xerogeanes J. Prevalence of saphenous nerve injury afert autogenous harmstring harvest: an anatomical and clinical study of sartorial branch injury. Arthroscopy 2007;23:956-63.

12. Warren F, Marshall JL. The supporting structures and layers on the medial side of the knee. J Bone Joint Surg 1979;61:56-62.

13. Bertram C, Porsch M, Hackenbroch MH, Terhaag D. Saphenous neuralgia after arthroscopically assisted anterior cruciate ligament reconstruction with a semitendinous and gracilis tendon graft. Arthroscopy 2000;16:763-6.

14. Hunter LY, Louis DS, Riccardi JR, O'Connor GA. The saphenous nerve: its course and importance in medial arthrotomy. Am J Sports Med 1979;7: 227-30.

15. Romanes GJ. Cunningham's Textbook of Anatomy; 11th Ed. London: Oxford Medical Education; 1972. p. 760.

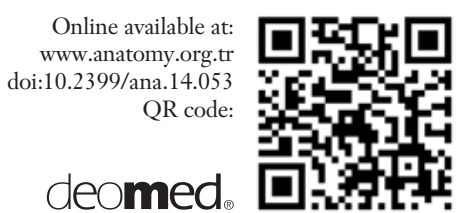

\author{
Correspondence to: Georg Christoph Feigl, MD \\ Institute of Anatomy, Medical University of Graz, \\ Harrachgasse 21, 8010, Graz, Austria \\ Phone: +43 3163804213 \\ e-mail: georg.feig|@medunigraz.at \\ Conflict of interest statement: No conflicts declared.
}

This is an open access article distributed under the terms of the Creative Commons Attribution-NonCommercial-NoDerivs 3.0 Unported (CC BY-NCND3.0) Licence (http://creativecommons.org/licenses/by-nc-nd/3.0/) which permits unrestricted noncommercial use, distribution, and reproduction in any medium, provided the original work is properly cited. Please cite this article as: Feigl GC, Anderhuber F. The "ghost" nerve alias sartorial branch of the saphenous nerve: a proof of scientific negligence! Anatomy 2015;9(2):112-114. 